\title{
Analisa Tegangan Pada Pipa Baja Karbon API 5L-GradeB Terhadap Laju Korosi Dalam Larutan NaCl dan Asam Asetat.
}

\author{
Nendi Suhendi Syafei ${ }^{1}$, Sri Suyaningsih ${ }^{2}$, Otong Nurhilal ${ }^{3}$, Febi Luthfiani ${ }^{4}$. \\ ${ }_{1,2,3,4}$ Departemen Fisika FMIPA Universitas Padjadjaran \\ Jalan Raya Bandung - Sumedang Km. 21 Jatinangor Kode Pos 45363 , telepon : 022-7796014. Hp. +62 82128152293 \\ email : n.suhendi@phys.unpad.ac.id; nsuhendi59@gmail.com
}

\begin{abstract}
Abstrak - Efisiensi pemakaian energi untuk suatu kebutuhan harus dilakukan agar pemborosan energi dapat dihindarkan dengan melakukan pemilihan dan pemeliharaan peralatan logam. Korosi menjadi permasalahan utama pada industri minyak bumi dan gas karena dapat menghambat proses produksi. Korosi retak tegang (SCC, Stress Corrosion Cracking) adalah peristiwa pembentukan dan perambatan retak dalam logam yang terjadi secara simultan antara tegangan yang bekerja pada bahan dengan lingkungan yang korosif. Dalam penelitian ini digunakan rumah sampel dengan spesimen tiga titik pembebanan untuk melihat perilaku korosi retak tegang pada pipa baja karbon di lingkungan gas $\mathrm{H}_{2} \mathrm{~S}$ kondisi jenuh $\mathrm{CO}_{2}$ dalam larutan $\mathrm{NaCl}$ dan Asam Asetat . Dalam larutan $\mathrm{NaCl}$ tidak terjadi korosi retak tegang (crack) pada baja karbon dengan laju korosi minimum 0,071 mmpy dan laju korosi maksimum 0,092 mmpy. Dalam larutan asam asetat terjadi korosi retak tegang (crack) pada baja karbon dengan laju korosi 0,25 mmpy dan 0,29 mmpy.
\end{abstract}

Kata kunci: SCC, spesimen tiga titik, retak tegang.

Abstract - The efficiency of energy use to a need to do so that energy wastage can be avoided by doing the selection and maintenance of metal equipment. Corrosion becomes a major issue in the oil and gas industry because it can inhibit the production process. Stress corrosion cracking (SCC, stress corrosion cracking) is an incident crack formation and propagation in metals that occur simultaneously between the stress acting in the material to a corrosive environment. This study used a sample home with three specimen loading point to see the behavior of the stress corrosion cracking of carbon steel pipe in the $\mathrm{H} 2 \mathrm{~S}$ gas $\mathrm{CO} 2$ saturated $\mathrm{NaCl}$ solution and Acetic Acid. In $\mathrm{NaCl}$ solution does not occur stress corrosion cracking (crack) in carbon steel with a minimum of $0.071 \mathrm{mmpy}$ corrosion rate and maximum corrosion rate of 0.092 mmpy. In a solution of acetic acid occurs stress corrosion cracking (crack) in carbon steel with a corrosion rate of 0.25 and 0.29 mmpy.

Keywords: SCC, specimens of three points, stress cracking.

\section{I.PENDAHULUAN.}

Dalam rangka penyediaan energi nasional bahwa terjadi menurunnya tingkat produksi minyak bumi menjadi permasalahan yang harus diatasi. Pada sumur produksi di industri migas, saluran pipa buangan, maupun hasil pengolahan biasanya mengandung gas $\mathrm{H}_{2} \mathrm{~S}$ dan $\mathrm{CO}_{2}$. Umumnya saluran migas mengeluarkan gas tersebut dengan jumlah relatif besar yang dapat menimbulkan korosi dan berperan sebagai faktor korosi internal. Pada umumnya keadaan sumur migas di Indonesia telah digunakan dalam jangka waktu cukup lama, maka membutuhkan reinjeksi fluida untuk mendorong hidrokarbon yang terjebak pada reservoir dibawah lapisan bumi. Akibatnya tidak hanya hidrokarbon yang keluar tetapi disertai air, $\mathrm{H}_{2} \mathrm{~S}, \mathrm{CO}_{2}$ dan sejumlah gas penyerta bersifat sangat korosif (sweet gas) terhadap pipa baja karbon untuk menyalurkan hidrokarbon.

Korosi yang disebabkan oleh sweet gas pada tekanan yang tinggi disebut korosi retak tegang (SCC), dan termasuk salah satu penyebab kegagalan pipa berakhir pipa pecah yang dijumpai di berbagai industri migas bahkan di pembangkit listrik lain seperti pada gambar (1). Korosi tidak dapat dihindari maka agar korosi tidak terlalu merugikan diperlukan upaya pencegahan untuk menekan tingkat laju korosi serendah mungkin serta umur ketahanan material yang lebih lama. Maka dilakukan kajian perilaku korosi retak tegang pada pipa baja karbon dilingkungan sweet gas agar dapat diprediksi pola penjalaran retak, sehingga akhirnya dapat memprediksi umur sisa dari pipa baja karbon.
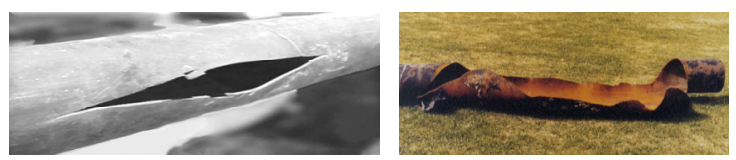

Gambar 1. Kerusakan pipa akibat peristiwa korosi SCC.

\section{LANDASAN TEORI \\ Korosi Retak Tegangan}

Korosi retak tegang terjadi akibat stress yang tinggi pada media korosif secara bersamaan. Penyebab terjadi korosi retak tegang yaitu pertama: material yang meliputi sifat komposisi kimia, sifat heat treatment pada saat pembuatan, mikrostruktur, serta kehalusan permukaan material. Kedua: lingkungan korosif yang meliputi komposisi kimia fluida (gas), suhu dan laju aliran. Ketiga: tegangan dan regangan meliputi tegangan dipermukaan, tegangan pada saat fit-up dan tegangan residual [1]. Peristiwa korosi retak tegangan (SCC) ditunjukkan seperti pada gambar (2).

Pipa Baja Karbon adalah paduan besi dan karbon yang mengandung beberapa unsur lain seperti sulfur, pospor, nickel dan mangan serta sejumlah unsur lainnya dalam persentase yang sangat kecil. Baja karbon rentan terhadap korosi, yaitu adanya beban internal (tekanan fluida dari dalam pipa yang memberikan tegangan 
terhadap dinding pipa), atau beban eksternal (beban konsentrasi dibeberapa tempat tertentu misalkan pada sambungan/belokan dan disekitar katup (valve)).

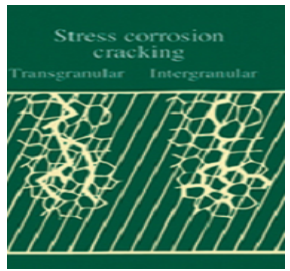

Gambar 2. Skema korosi retak tegangan (SCC)[2].

Pengaruh lingkungan terhadap korosi retak tegang bahwa lingkungan kimiawi bersifat unik terhadap logam yang digunakan, misalnya $\mathrm{HCl}$ akan cepat merusak stainless steel tetapi tidak merusak baja karbon dan paduan non ferrous lainnya. Sedangkan lingkungan yang mengandung air, $\mathrm{CO}, \mathrm{CO}_{2}, \mathrm{H}_{2} \mathrm{~S}$, dan $\mathrm{NH}_{4}$ sangat korosif terhadap baja karbon dan low alloy steel.

Lingkungan yang menyebabkan korosi retak tegang dipengaruhi oleh: (a). Adanya ion agresif. Ion agresif yang merusak logam diantaranya adalah ion klorida, sulfat dan nitrat. (b). Pengaruh temperatur. Pada umumnya kenaikkan temperatur akan meningkatkan laju korosi karena pada temperatur tinggi kelarutan zat kimia semakin meningkat. (c).Pengaruh $\mathrm{pH}$. Logam memiliki laju korosi yang berbeda untuk setiap rentang $\mathrm{pH}$. Pada semua kondisi $\mathrm{pH}$ reaksi anodik akan terjadi, $\mathrm{pH}$ 4-10 bahwa oksida yang bersifat porous melindungi permukaan dan menjaga $\mathrm{pH}$ sekitar 9,5 dibawah deposit oksida. Pada kondisi ini laju korosi konstan dan korosi disebabkan difusi oksigen yang terlarut disekitar deposit, dan permukaan logam dibawah deposit terjadi reaksi katodik yaitu akibat $\mathrm{O}_{2}$ yang mereduksi.

Pada larutan asam dengan $\mathrm{pH}$ dibawah 7 oksida terlarut, sehingga korosi akan meningkat dan menghasilkan hidrogen. Pada $\mathrm{pH}$ diatas 10, reaksi korosi cenderung membentuk lapisan pasivasi dipermukaan logam, sedangkan air yang mengandung ion bikarbonat dan klorida memberikan laju korosi yang sangat tinggi pada $\mathrm{pH}$ disekitar 8 dan membentuk korosi pitting.

Laju Korosi di definisikan sebagai banyaknya logam yang dilepas tiap satuan waktu pada permukaan tertentu [3], satuannya adalah mil per year (mpy). Metode kehilangan berat adalah perhitungan laju korosi dengan mengukur kekurangan berat [4] akibat korosi yang terjadi, dan ditujukkan pada persamaan (1) :

$$
C R(\text { rrey })-\frac{534 w}{D A T}
$$

dengan:

$\mathrm{CR}=$ Corrosion Rate, (laju korosi) (mpy), mpy = mils per year (satu per seribu inchi per tahun), $\mathrm{W}=$ berat yang hilang (mg), D = massa jenis sampel $\left(9 / \mathrm{cm}^{3}\right), \mathrm{A}=$ luas sampel $\left(m^{2}\right), \mathrm{T}=$ waktu yang diperlukan (hour).
Hubungan laju korosi dengan ketahanan korosinya (relative) dikatagorikan sebagai kondisi buruk, kurang, cukup, baik, sangat baik dan sangat baik sekali [5].

\section{METODE PENELITIAN.}

Metode penelitian dengan pendekatan kuantitatif ini terdiri dari: (a). Studi Literatur; (b) persiapan sampel (baja karbon, holder spesimen tiga titik pembebanan, agen korosi); (c) pelaksanaan percobaan di Laboratorium; (d) pengukuran laju korosi dan morfologi bahan; (e) analisa data. Diagram alir penelitian, seperti pada gambar 3.

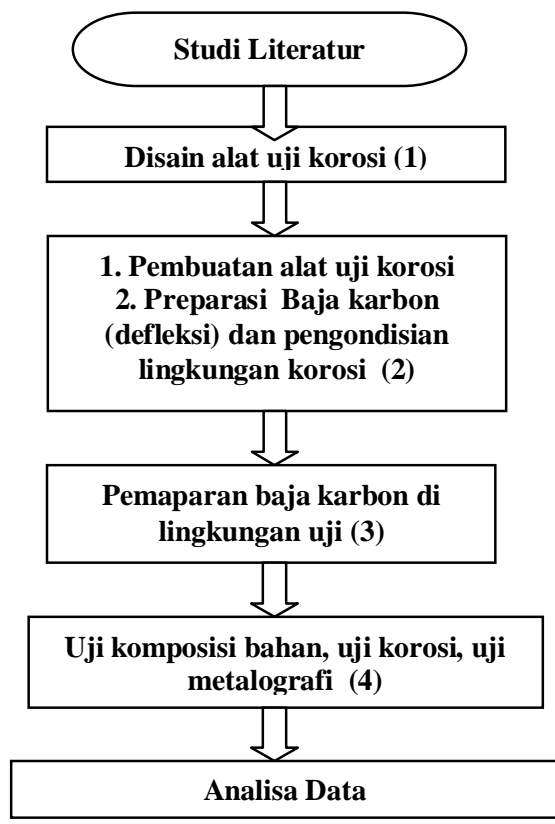

Gambar 3. Diagram Alir Penelitian.

\section{HASIL DAN PEMBAHASAN.}

\section{Hasil Uji Komposisi Material Uji}

Terlihat pada Tabel 1, dan hasil uji komposisi baja karbon terdiri dari kandungan Ni sebesar 0,026\% dan $\mathrm{Cr}$ sebesar 0,015\%. Hasil tersebut sesuai dengan dibandingkan baja karbon umumnya yang memiliki kadar Ni sekitar $0.02 \%$ dan $\mathrm{Cr}$ sekitar $0.019 \%$.

Kandungan Mn dapat meningkatkan kekuatan, kekerasan, kemampuan untuk dapat ditempa menyeluruh, ketahanan aus, penguatan pada pembentukan dingin, tetapi menurunkan kemampuan serpih.

Hasil uji kandungan Mn sebesar $0.689 \%$, kandungan C sebesar $0.137 \%$. Karbon merupakan unsur pengeras besi yang efektif dan murah, dan umumnya sebagian besar baja hanya mengandung karbon dengan sedikit unsur paduan lainnya.

Berdasarkan kandungan karbon bahwa pipa API-5L-Gr $B$ termasuk baja yang mengandung karbon kurang dari $0,3 \%$. 
Tabel 1. Hasil Komposisi Unsur Sampel Uji Dengan Menggunakan Spektrometer ARL 3460.

\begin{tabular}{|c|c|c|c|c|c|}
\hline No. & Unsur/Elemen & $\begin{array}{l}\text { Nilai } \\
(\%)\end{array}$ & No. & Unsur Elemen & $\begin{array}{l}\text { Nilai } \\
(\%)\end{array}$ \\
\hline 1. & $\begin{array}{l}\text { Carbon } \\
\text { (C) }\end{array}$ & 0,13667 & 11. & $\begin{array}{c}\text { Walfram/Tungsen } \\
\text { (W) }\end{array}$ & 0,00234 \\
\hline 2. & $\begin{array}{l}\text { Silikon } \\
(\mathrm{Si})\end{array}$ & 0,01096 & 12. & $\begin{array}{l}\text { Titanium } \\
\text { (Ti) }\end{array}$ & 0,00150 \\
\hline 3. & $\begin{array}{l}\text { Sulfur } \\
(\mathbf{S})\end{array}$ & 0,01174 & 13. & $\begin{array}{l}\text { Tin } \\
\text { (Sn) }\end{array}$ & 0,00312 \\
\hline 4. & $\begin{array}{c}\text { Phosphorus } \\
\text { (P) }\end{array}$ & 0,00419 & 14. & $\begin{array}{c}\text { Aluminium } \\
(\mathrm{Al})\end{array}$ & 0,02971 \\
\hline 5. & $\begin{array}{l}\text { Manganese } \\
\text { (Mn) }\end{array}$ & 0,68884 & 15. & $\begin{array}{c}\text { Plumbun/Lead } \\
(\mathrm{Pb})\end{array}$ & 0,00048 \\
\hline 6. & $\begin{array}{l}\text { Nickel } \\
\text { (Ni) }\end{array}$ & 0,02578 & 16. & $\begin{array}{l}\text { Amtimony } \\
\text { (Sb) }\end{array}$ & 0,00000 \\
\hline 7. & $\begin{array}{l}\text { Chromium } \\
\text { (Cr) }\end{array}$ & 0,01510 & 17. & $\begin{array}{l}\text { Niobium } \\
(\mathrm{Nb})\end{array}$ & 0,00000 \\
\hline 8. & $\begin{array}{l}\text { Molybdenum } \\
\text { (Mo) }\end{array}$ & 0,00510 & 18. & $\begin{array}{l}\text { Zirconium } \\
(\mathbf{Z r})\end{array}$ & 0,00000 \\
\hline 9. & $\begin{array}{c}\text { Vanadium } \\
(\mathbf{V})\end{array}$ & 0,00391 & 19. & $\begin{array}{l}\text { Zinc } \\
(\mathbf{Z n})\end{array}$ & 0,00141 \\
\hline 10. & $\begin{array}{l}\text { Copper } \\
\text { (Cu) }\end{array}$ & $\mathbf{0 , 0 4 3 9 0}$ & 20. & $\begin{array}{c}\text { Ferro/Iron } \\
(\mathrm{Fe})\end{array}$ & 99,02020 \\
\hline
\end{tabular}

\section{Hasil Uji Korosi Sampel}

Perhitungan laju korosi terhadap variasi tegangan dinyatakan dalam besarnya defleksi (y). Hasil uji korosi sampel variasi tegangan dan waktu perendaman dalam Larutan $\mathrm{NaCl} 3,5 \%, \mathrm{H}_{2} \mathrm{~S}$ dan jenuh $\mathrm{CO}_{2}$ ditunjukkan pada Tabel 2.

Tabel 2. Laju Korosi Variasi Tegangan dan Waktu dalam Larutan $\mathrm{NaCl} 3,5 \%, \mathrm{H}_{2} \mathrm{~S}$ dan jenuh $\mathrm{CO}_{2}$ pada Suhu Ruang

\begin{tabular}{|c|c|c|c|c|c|c|}
\hline \multirow[b]{2}{*}{ No } & \multirow[b]{2}{*}{$\begin{array}{c}\text { Sampel } \\
(\mathbf{c m})\end{array}$} & \multirow[b]{2}{*}{$\begin{array}{c}\text { Waktu } \\
\text { (jam) }\end{array}$} & \multicolumn{2}{|c|}{$\begin{array}{c}\text { Berat Plat yang } \\
\text { dikorosikan }\end{array}$} & \multirow{2}{*}{$\begin{array}{c}\text { Selisih } \\
\text { Berat } \\
\text { (g) }\end{array}$} & \multirow{2}{*}{$\begin{array}{c}\text { Laju } \\
\text { Korosi } \\
\text { (mmpy) }\end{array}$} \\
\hline & & & $\begin{array}{c}\text { Sebelum } \\
(\mathrm{g})\end{array}$ & $\begin{array}{c}\text { sesudah } \\
(\mathrm{g})\end{array}$ & & \\
\hline 1 & $\begin{array}{l}A ; \\
y=1,70\end{array}$ & 48 & 47.374 & 47.338 & $\mathbf{0 . 0 3 5 6}$ & 0.071 \\
\hline 2 & $\begin{array}{l}B ; \\
y=2,22\end{array}$ & 48 & 48.072 & 48.028 & 0.0439 & 0.087 \\
\hline 3 & $\begin{array}{l}\mathrm{C} ; \\
\mathrm{y}=2,74\end{array}$ & 48 & 48.240 & 48.195 & 0.0451 & 0.090 \\
\hline 4 & $\begin{array}{l}A ; \\
y=1,70\end{array}$ & 240 & 48.704 & 48.601 & 0.1026 & 0.082 \\
\hline 5 & $\begin{array}{l}\text { B ; } \\
y=2,22\end{array}$ & 240 & 47.574 & 47.729 & 0.1157 & 0,092 \\
\hline 6 & $\begin{array}{l}C ; \\
y=2,74\end{array}$ & 240 & 47.845 & 47.449 & 0.1248 & 0,099 \\
\hline
\end{tabular}

Laju korosi sampel yang direndam dalam larutan asam asetat $\left(\mathrm{CH}_{3} \mathrm{COOH}\right)$, gas $\mathrm{CO}_{2}$ dan gas $\mathrm{H}_{2} \mathrm{~S}$ selama 600 jam, yaitu seperti pada Tabel 3 .

Tabel 2 dan Gambar 4 menunjukkan hasil uji retak tegang (SCC) belum terjadi crack pada sampel dengan defleksi terkecil dan waktu rendam terpendek, yaitu sampel A ( $\mathrm{y}=1,70 \mathrm{~cm}$, waktu 48 jam) di lingkungan gas $\mathrm{H}_{2} \mathrm{~S}$ dan $\mathrm{CO}_{2}$ yang dijenuhkan dengan larutan $\mathrm{NaCl}$ dengan laju korosi merata 0,071 mpy. Sedangkan untuk sampel dengan defleksi terbesar dan waktu terlama, yaitu sampel C ( $=2,74 \mathrm{~cm}$, waktu 240 jam) nilai laju korosi homogen 0,099 mpy. Hal ini menunjukkan ada kecenderungan munculnya crack walupun masih sangat halus dikarenakan waktu perendaman yang diberikan untuk uji korosi tidak lama, dan tegangan yang diberikanpun sangatlah kecil. Tetapi hasil uji metalografi menunjukkan sudah adanya aktifitas korosi, yaitu terkikisnya permukaan sampel oleh media korosif.
Tabel 3. Hasil Laju Korosi Baja Karbon Dalam Larutan Asam Asetat, Gas $\mathrm{CO}_{2}$ Dan $\mathrm{H}_{2} \mathrm{~S}$ Selama 600 Jam.[6]

\begin{tabular}{|c|c|c|c|c|c|}
\hline \multirow{2}{*}{$\begin{array}{c}\text { Sampel } \\
\text { Uji }\end{array}$} & $\begin{array}{c}\text { Defleksi } \\
(\mathrm{cm})\end{array}$ & \multicolumn{2}{|c|}{ Massa Sampel (gr) } & $\begin{array}{c}\text { Selisih } \\
\text { Massa } \\
\text { (gr) }\end{array}$ & $\begin{array}{c}\text { Laju } \\
\text { Korosi } \\
(\mathrm{mmpy})\end{array}$ \\
\hline D & 2,7 & 29,2307 & 29,096 & $\mathbf{0 , 1 3 4}$ & $\mathbf{0 , 0 4}$ \\
E & 2,9 & 29,0741 & 28,9243 & 0,1498 & 0,05 \\
\hline
\end{tabular}

Sedangkan Tabel 3 dan Gambar 5 menunjukkan hasil uji retak tegang $(\mathrm{SCC})$ pada sampel $\mathrm{D}(\mathrm{y}=2,70 \mathrm{~cm}$, waktu 600 jam) di lingkungan gas $\mathrm{H}_{2} \mathrm{~S}$ dan $\mathrm{CO}_{2}$ yang dijenuhkan dengan larutan Asam Asetat $\left(\mathrm{CH}_{3} \mathrm{COOH}\right)$ terjadi crack dengan laju korosi 0,040 mpy. Sedangkan sampel dengan defleksi terbesar dan waktu terlama, yaitu sampel C ( $\mathrm{y}=2,90 \mathrm{~cm}$, waktu 600 jam) nilai laju korosi homogen 0,050 mpy dimana terlihat retakan cenderung putus. Jadi, semakin besar tegangan yang ditunjukkan dalam variasi defleksi semakin besar laju korosi homogen.

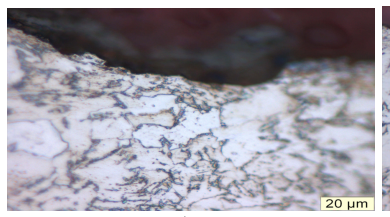

a)

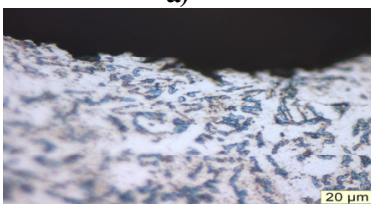

c)

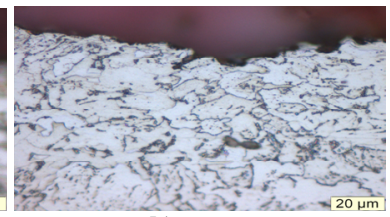

b)
Gambar 4 Hasil mikrostruktur perbesaran 50x sampel uji di rendam selama 240 jam dalam $\mathrm{NaCl}$, gas $\mathrm{H}_{2} \mathrm{~S}$, dan $\mathrm{CO}_{2}$ pada defleksi: a) $1,7 \mathrm{~cm}$, b) $2,22 \mathrm{~cm}$, dan c) $2,74 \mathrm{~cm}$.

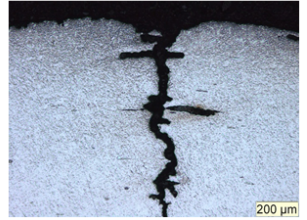

a)

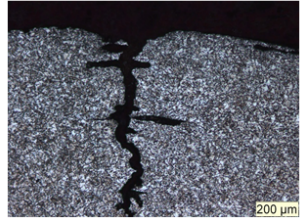

b)
Gambar 5. Hasil uji metalografi baja karbon dengan perbesaran $5 \mathrm{x}$ baja karbon yang direndam dalam larutan asam asetat, gas $\mathrm{CO}_{2}$ dan gas $\mathrm{H}_{2} \mathrm{~S}$ selama 600 jam (a) sebelum di etsa; (b) sesudah di etsa.[6]

Pembahasan selanjutnya diutamakan pada baja karbon yang direndam dalam larutan asam asetat, gas $\mathrm{CO}_{2}$ dan gas $\mathrm{H}_{2} \mathrm{~S}$, hal ini disebabkan logam terjadi crack dan untuk mengetahui hubungan retak tegang terhadap laju korosi perlu analisa terhadap hasil uji SEM-EDS, seperti ditunjukkan pada Tabel 4 . 
Tabel 4. Hasil Uji SEM Komposisi Unsur Logam Baja Karbon dalam larutan asam asetat, gas $\mathrm{CO}_{2}$ dan gas $\mathrm{H}_{2} \mathrm{~S}$.[6]

\begin{tabular}{|c|c|c||c|c|}
\hline & \multicolumn{4}{|c|}{ Uji Komposisi Kimia (\%) } \\
\hline Unsur & $\begin{array}{c}\text { Sebelum } \\
\text { diberi } \\
\text { perlakuan }\end{array}$ & $\begin{array}{c}\text { Setelah } \\
\text { diberi } \\
\text { perlakuan } \\
\text { asam } \\
\text { asetat }\end{array}$ & $\begin{array}{c}\text { Unsur } \\
\text { Pengotor }\end{array}$ & $\begin{array}{c}\text { Setelah } \\
\text { diberi } \\
\text { perlakuan } \\
\text { asam } \\
\text { asetat }\end{array}$ \\
\hline $\mathrm{C}$ & 37,25 & 19,62 & $\mathrm{C}$ & 10,74 \\
\hline $\mathrm{O}$ & 2,37 & 37,26 & - & - \\
\hline $\mathrm{Si}$ & 0,13 & 0,08 & $\mathrm{SiO} 2$ & 0,30 \\
\hline $\mathrm{Fe}$ & 59,84 & 42,75 & $\mathrm{FeO}$ & 88,98 \\
\hline
\end{tabular}

Kadar besi (Fe) mengalami penurunan dari 59,84\% menjadi $42,75 \%$, karena terjadinya pengikisan akibat korosi yang terjadi dalam bentuk $\mathrm{FeO}$ sebesar $88,98 \%$. Fe sebagai unsur utama pada baja karbon teroksidasi di larutan asam asetat, gas $\mathrm{CO}_{2}$ dan gas $\mathrm{H}_{2} \mathrm{~S}$.

\section{Hasil Uji Kekerasan}

Uji kekerasan bertujuan untuk menunjukan adanya indikasi tegangan dalam yang terjadi pada kontruksi. Parameter fisis yang diukur adalah kekerasan Rockwell (HRB) yang kemudian dikonversi ke kekerasan Brinnell (HB), dan selanjutnya dikonversi ke kekerasan tegangan. Pengujian sampel uji menggunakan pembebanan $150 \mathrm{Kg}$, penetrator yang digunakan adalah diamond cone dan hasil pengujian kekerasan seperti pada Tabel 5. Hasil tegangan baja karbon sebesar 70.227 psi yang termasuk tinggi karena pada daerah tersebut terjadi peningkatan kekerasan akibat adanya tegangan yang diberikan dari hasil defleksi sebesar $2,7 \mathrm{~cm}$ dan 2,9 cm. Ketika di dua defleksi terjadi pengerasan total, ini akan mempengaruhi terhadap efek korosi yang terjadi, dan akan menimbulkan efek korosi yang berbeda. Sehingga terjadi peningkatan efek korosi dari sebelumnya.

Tabel 5. Hasil Pengujian Kekerasan Baja Karbon

\begin{tabular}{|c|c|c|c|c|c|}
\hline Titik & HRB & $\begin{array}{c}\text { Rata- } \\
\text { Rata } \\
\text { (HRB) }\end{array}$ & $\begin{array}{l}\text { Rata- } \\
\text { Rata } \\
\text { (HB) } \\
\end{array}$ & $\sigma$ (Psi) & $\begin{array}{c}\sigma \\
\text { (Mpa) }\end{array}$ \\
\hline I & 76 & \multirow{5}{*}{76,5} & \multirow{5}{*}{136} & \multirow{5}{*}{70.227} & \multirow{5}{*}{484,20} \\
\hline II & 77 & & & & \\
\hline III & 77 & & & & \\
\hline IV & 76 & & & & \\
\hline V & 76 & & & & \\
\hline
\end{tabular}

Hasil perhitungan tegangan maksimum $(\sigma)$ untuk setiap sampel baja karbon, dimana defleksi (y), tebal sampel (t), dan panjang sampel $(\mathrm{H})$ diukur langsung ditunjukkan pada Tabel 6.

Tabel 7. menunjukkan jumlah nilai stress $(\sigma)$. Ketika y $=2,7 \mathrm{~cm}$, nilai total jumlah stress $(\sigma)$ adalah $641.424 \mathrm{psi}$ sedangkan $\mathrm{y}=2,9 \mathrm{~cm}$ diperoleh nilai total jumlah tegangan $(\sigma)$ adalah sebesar 683.735 psi.
Tabel 6. Hasil Perhitungan Tegangan Maksimum Dari Defleksi Sampel.[6]

\begin{tabular}{|c|c|c|c|c|c|}
\hline $\begin{array}{c}\text { Sampel } \\
\mathbf{U j i}\end{array}$ & $\mathbf{t}(\mathbf{m})$ & $\mathbf{y}(\mathbf{m})$ & $\begin{array}{c}\mathbf{H} \\
(\mathbf{m})\end{array}$ & $\boldsymbol{\sigma}\left(\mathbf{N} / \mathbf{m}^{2}\right)$ & $\boldsymbol{\sigma}(\mathbf{p s i})$ \\
\hline $\mathrm{D}$ & 0,00015 & 0,027 & 0,125 & $3,94 \times 10^{8}$ & 571.197 \\
$\mathrm{E}$ & 0,00015 & 0,029 & 0,125 & $4,23 \times 10^{8}$ & 613.508 \\
\hline
\end{tabular}

Tabel 7. Jumlah total nilai stress dalam satuan psi dengan variasi deflkesi $2,7 \mathrm{~cm}$ dan $2,9 \mathrm{~cm}$.

\begin{tabular}{|c|c|c|c|c|c|}
\hline No & $\begin{array}{c}\text { Tegangan } \\
\text { di Notch } \\
\text { Area } \\
\text { (psi) }\end{array}$ & $\begin{array}{c}\sigma 1 \\
(\text { Psi), } \\
\mathbf{y}=2.7 \\
\text { cm }\end{array}$ & $\begin{array}{c}\sigma 2 \\
(\text { Psi), } \\
y=2.9 \\
\text { cm }\end{array}$ & $\begin{array}{l}\text { Jumlah } \\
\text { б1 (Psi) }\end{array}$ & $\begin{array}{l}\text { Jumlah } \\
\text { б2 (Psi) }\end{array}$ \\
\hline 1 & 70.227 & 571.197 & 613.508 & 641.424 & 683.735 \\
\hline
\end{tabular}

Tegangan dan waktu perendaman sangat mempengaruhi laju korosi, terutama untuk SCC. Semakin besar tegangan yang diberikan dan semakin lama waktu perendaman, maka laju korosi akan semakin besar. Selain itu, elektrolit-elektrolit dari media perendaman akan mudah masuk dan menimbulkan serangan korosi pada permukaan dengan tegangan yang besar.

\section{KESIMPULAN}

Pipa baja karbon yang direndam dalam larutan natrium klorida, gas $\mathrm{CO}_{2}$ dan gas $\mathrm{H}_{2} \mathrm{~S}$ dengan defleksi $1,7 \mathrm{~cm}$, 2,22 cm, dan 2,74 cm masing-masing selama 48 jam dan 240 jam tidak terjadi crack dengan variasi laju korosi antara 0,071 mpy - 0,099 mmpy. Pipa baja karbon yang direndam dalam larutan asam asetat, gas $\mathrm{CO}_{2}$ dan gas $\mathrm{H}_{2} \mathrm{~S}$ selama 600 jam dengan defleksi $2,7 \mathrm{~cm}$ dan $2,9 \mathrm{~cm}$ terjadi crack dengan laju korosi 0,040 mpy dan 0,05 mmpy. Jadi semakin besar tegangan semakin besar laju korosi homogen.

\section{UCAPAN TERIMA KASIH}

Ucapan terima kasih pada FMIPA UNPAD melalui DIPA BLU UNPAD dan Departemen Fisika UNPAD yang telah memberikan bantuan selama penelitian.

\section{PUSTAKA}

[1] Alkazraji, Duraid. 2008. Pipeline Engineering. Cambridge England: Woodhead Publishing Limited.

[2] R Winston Revie, Uhlig's Corrosion Handbook Thrid Edition, The Electrochemical Society, Inc., Jhon Wiles \& Sons, Inc., Publication, 2011.

[3] M. G. Fontana. 1986. Corrosion Engineering. New York : McGraw-Hill.

[4] ASTM G1 - 93. Standard Terminology and Acronyms Relating to Corrosion.

[5] Callister, D. William. 2007. Materials Science an Engineering: an Intruduction $7^{\text {th }} \mathrm{ed}$. United States of America: John Wiley \& Sons, Inc.

[6] Febi Luthfiani, 2015, Analisis Pengaruh Gas $\mathrm{CO}_{2}$ Dan $\mathrm{H}_{2} \mathrm{~S}$ Terhadap Laju Korosi Retak Tegangan Pada Pipa Baja Karbon Dalam Larutan Asam Asetat Glasial 5\%, Skripsi, Program Studi Fisika FMIPA Universitas Padjadjaran. 